\title{
EDITORIAL
}

\section{CALIDAD Y SEGURIDAD DE LA ATENCIÓN}

\author{
QUALITY AND SAFETY OF CARE
}

Dra. María Guadalupe Moreno Monsiváis

Facultad de Enfermería. Universidad Autónoma de Nuevo León.

MÉXICO

\begin{abstract}
T a calidad y seguridad de la atención es hoy en día una prioridad a nivel mun$\smile$ dial y en todos los niveles asistenciales. Garantizar que la atención que se proporciona a los usuarios cumple con los estándares internacionales de calidad y los protege de riesgos inherentes al sistema de salud, es un reto que requiere el compromiso de todos los involucrados en el área de la salud (1).
\end{abstract}

Entre los principales involucrados y responsables de la calidad y seguridad de la atención podemos destacar tres ámbitos fundamentales: el clínico, el formativo y el del usuario receptor de la atención. La sinergia entre estos tres ámbitos se considera el eje estructural para garantizar una atención libre de riesgo y que contribuya a mejorar los resultados en la salud de la población.

En relación con el ámbito clínico, integrado por las instituciones de salud y los proveedores de atención, se requiere: a) Contar con políticas institucionales donde se posicione la calidad y la seguridad del paciente como el eje central de la atención y establecer procesos de gestión dirigidos al cumplimiento de las políticas, b) Establecer un proceso de vigilancia continua de la calidad de la atención con mecanismos de control y monitoreo bien definidos, que permitan evaluar los resultados e implementar medidas de mejora y correctivas en caso necesario y, c) Desarrollar una cultura de calidad y seguridad, donde el hacer las cosas bien y libres de riesgo sea un compromiso que involucre a todos los niveles de la organización y permita transitar a un comportamiento consciente de la necesidad de asegurar un ambiente de calidad y seguridad, donde no exista temor a notificar los errores y el reporte se convierta en una oportunidad de aprendizaje a nivel individual y organizacional. 
Así mismo, se requiere que en todas las instituciones de salud se cuente con programas permanentes de educación continua, donde se mantenga actualizado al personal en los procesos de atención con apego estricto a los estándares internacionales de calidad y seguridad. Estos programas deben ser dirigidos a todo el personal, con énfasis en los de nuevo ingreso, de tal forma que se garantice que al incorporarse a la atención, cuenten con las competencias adecuadas para brindar un servicio de calidad y libre de riesgos (2).

En cuanto al ámbito formativo, las instituciones educativas formadoras de recursos humanos para el área de la salud requieren contar con planes de estudio que incorporen transversalmente la temática de calidad y seguridad, esto contribuye a que todo profesional en formación conozca su contribución y responsabilidad en el cumplimiento de los estándares internacionales de calidad y seguridad. En este sentido, la formación de los profesionales de enfermería se considera un factor clave, su presencia y permanencia en los servicios de salud sitúan a las enfermeras en una condición crítica, tanto por el riesgo de error como por su capacidad y potencialidad para promover la seguridad de los pacientes. Su participación en la mayoría de los procesos de atención, así como su involucramiento con todo el equipo de salud, demanda que su formación garantice su competencia para desarrollar un rol activo a favor de la calidad y la seguridad en la atención (3).

Finalmente, respecto al ámbito del usuario receptor de la atención, promover su participación ciudadana en temas de calidad y seguridad es fundamental para lograr sistemas de salud más seguros. El empoderamiento del paciente se considera una medida crucial, la OMS define el empoderamiento como el proceso a través del cual las personas obtienen control sobre las decisiones y acciones que afectan su salud. Esto implica desarrollar la comprensión del paciente de su propio rol en la promoción, mantenimiento, vigilancia y restablecimiento de su salud, así como el conocimiento y las habilidades suficientes para poder involucrarse en la mejora de su salud; además de lo anterior, es fundamental la presencia de un ambiente facilitador para su participación (4).

Para lograr el reto de la calidad y la seguridad de la atención se requiere un compromiso institucional, multidisciplinario, interdisciplinario y a nivel individual tanto por parte de los proveedores como por el propio usuario receptor de la atención. La contribución de todos y cada uno de los actores sociales involucrados en el ámbito de la salud permitirá garantizar que la atención que se proporcione cumpla con los estándares de calidad y sea libre de riesgo para todos los usuarios; la co-responsabilidad de todos es fundamental. Existe evidencia de múltiples avances, a nivel local, nacional e internacional; sin embargo, las diferencias en la calidad y seguridad que se proporciona en las diversas instituciones 
siguen siendo notorias, se requiere un mayor esfuerzo para afirmar que la atención que se proporciona a todo usuario independientemente del tipo de institución a la que acuda a solicitar atención, es de calidad y libre de riesgo.

\section{REFERENCIAS}

1. Organización Mundial de la Salud (OMS). Marco Conceptual de la Clasificación Internacional para la Seguridad del Paciente. Ginebra: OMS; 2009.

2. Organización Panamericana de la Salud (OPS). Enfermería y seguridad de los pacientes. Washington, DC:OPS; 2011.

3. Covell CL.The middle range theory of nursing intellectual capital. Journal of Advanced Nursing. 2008; 63(1): 94-103.

4. Leape L, Berwick D, Clancy C, Conway J, Gluck P, Guest J, et al. Transforming healthcare: a safety imperative. Qual Saf Health Care. 2009; 18(6): 424-428. 